\title{
The digestive system of 1 -week-old Jersey calves is well suited to digest, absorb, and incorporate protein and energy into tissue growth even when calves are fed a high plane of milk replacer ${ }^{1}$
}

\author{
Yu Liang, ${ }^{*}$ Jeffery A. Carroll, $†$ and Michael A. Ballou* ${ }^{* 2}$ \\ *Department of Animal and Food Sciences, Texas Tech University, Lubbock 79403 \\ †Livestock Issues Research Unit, USDA-ARS, Lubbock, TX 79403
}

\section{ABSTRACT}

The objectives of the current study were to determine the apparent digestibilities of nitrogen, organic matter, ash, and energy as well as investigate the nitrogen retention of calves fed different planes of milk replacer nutrition during the first week of life. Twelve Jersey calves were blocked by body weight at birth and randomly assigned to either a high plane of nutrition (HPN) or low plane of nutrition (LPN) treatment. The HPN calves were offered $19.2 \mathrm{~g}$ of dry matter $/ \mathrm{kg}$ of body weight of a $28 \%$ all-milk crude protein and $20 \%$ fat milk replacer. The LPN calves were fed $11.6 \mathrm{~g}$ of dry matter $/ \mathrm{kg}$ of body weight of a $20 \%$ all-milk crude protein and $20 \%$ fat milk replacer. All calves were given $3 \mathrm{~L}$ of pooled colostrum within $1 \mathrm{~h}$ of birth after which they were assigned to treatments; no starter was offered during the study. Calves were given $1 \mathrm{~d}$ to adapt to their treatments and environment, so calves were 30 to $36 \mathrm{~h}$ old at the start of data collection. The study was divided into two 72-h periods. Total collection of feces occurred over each $72 \mathrm{~h}$ period, and total urine was collected for the last $24 \mathrm{~h}$ of each period. Peripheral blood samples were collected at the beginning and end of each period and analyzed for plasma glucose and urea nitrogen concentrations. Data are reported as HPN vs. LPN, respectively. Fecal scores were greater for HPN calves during both periods; however, no difference was found in the dry matter percentage of feces (30.9 vs. $31.9 \pm$ 0.06). No differences were found between treatments in either digestible or metabolizable energy efficiencies, which averaged 93.3 and $83.7 \%$, respectively. A treatment $\times$ period interaction was found on the percentage of intake nitrogen retained, in which calves fed

Received June 1, 2015.

Accepted November 8, 2015.

${ }^{1}$ Mention of trade names or commercial products in this article is solely for the purpose of providing specific information and does not imply recommendation or endorsement by the US Department of Agriculture.

${ }^{2}$ Corresponding author: michael.ballou@ttu.edu the HPN had a greater percentage of intake nitrogen retained during period 1 ( 87.9 vs. $78.4 \pm 1.79 \%$ ), but was not different from calves fed the LPN during period 2 (85.4 vs. $84.9 \pm 1.79 \%$ ). From these data therefore, we conclude that healthy neonatal calves have the capability to digest and absorb the additional nutrients with a higher plane of nutrition during the first week of postnatal life.

Key words: calf, digestibility, nutrition

\section{INTRODUCTION}

Dairy calves must adapt to the ex utero environment soon after birth. Many things change in calves' lives at parturition, including receiving all of their nutrients from milk rather than the placenta, as well as living in a dynamic, microbial environment rather than a more consistent and relatively sterile one. Therefore, this adaptation to the ex utero environment can be stressful and it is not surprising that the risk of morbidity and mortality are great during this period (NAHMS, 2007). The risk for gastrointestinal disease is the greatest during the first few weeks of life and is inversely proportional to the age of calves. The gastrointestinal tract of neonatal calves changes greatly during the first week of life, from more vacuolated to more adult-like enterocytes (Guilloteau et al., 2009). Those authors also reported that digestive enzyme secretions increased rapidly over the first $48 \mathrm{~h}$ after birth, but some functions of the gastrointestinal tract will further develop over the first month of life, for example, gastrointestinal motility. The integrity of the gastrointestinal tract influences not only digestion of nutrients but also the resistance to many infectious diseases.

One topic of interest is how plane of milk nutrition fed to dairy calves influences future lactational performance as well as health (Soberon et al., 2012; Ballou, 2012). Most data investigating the effects of plane of nutrition on enteric health primarily used the consistency of feces as the outcome variable (Nonnecke et al., 2003; Bartlett et al., 2006; Ballou, 2012). Many studies 
reported softer feces among calves fed higher planes of milk or milk replacer (Nonnecke et al., 2003; Bartlett et al., 2006), whereas others observed no difference (Ballou, 2012; Obeidat et al., 2013). Nonnecke et al. (2003) suggested that the softer feces among calves fed a higher plane of milk nutrition was likely associated with the greater consumption of DM and fluid rather than any difference in enteric health.

It is common for calves fed restricted quantities of milk to lose BW during the first week of life, whereas the BW of calves fed higher planes of nutrition will increase slightly during the first week (Nonnecke et al., 2003; Ballou, 2012; Obeidat et al., 2013). Plasma urea nitrogen concentrations among calves fed higher planes of nutrition are greater during the first week of life when compared with calves fed restricted quantities of milk (Obeidat et al., 2013; Ballou et al., 2015). After the first week, the plasma urea nitrogen concentrations decrease to concentrations similar as those observed among calves fed restricted quantities of milk. These data suggest that some of the additional digestible protein among calves fed a high plane of nutrition may not be used for protein synthesis during the first week of life. In addition, the apparent digestibilities of nutrients during the first week of life among calves fed different planes of milk nutrition are unknown.

The objectives of the current study were to determine the apparent digestibilities of energy and nitrogen as well as investigate the nitrogen retention of calves fed different planes of milk replacer nutrition during the first week of life. The hypothesis of this experiment was that calves fed higher planes of milk replacer nutrition would have increased total energy and nitrogen digestion, absorption, and greater nitrogen retention $(\mathrm{g} / \mathrm{d})$, but when expressed as a percentage of intake they would be reduced when compared with calves fed restricted quantities of milk replacer.

\section{MATERIALS AND METHODS}

\section{Calves and Treatments}

The experiment was conducted in March 2014. All animal procedures were reviewed and approved by the Livestock Issues Research Unit of the USDA-ARS animal care committee. Twelve Jersey bull calves were transported $150 \mathrm{~km}$ from a large commercial dairy to the temperature-controlled calf nursery at the Livestock Issues Research Unit in Lubbock, Texas. The nursery was maintained at $21 \pm 1.0^{\circ} \mathrm{C}$. All calves were born between 0000 and $0700 \mathrm{~h}$ of the enrollment date (referred to as age $0 \mathrm{~d}$ ). The calves were picked up from the dairy at $0800 \mathrm{~h}$ and a peripheral blood sample was collected immediately into an evacuated tube without any additive. Serum was collected after centrifugation at $1,200 \times g$ for $15 \mathrm{~min}$ at $23^{\circ} \mathrm{C}$ upon arrival at the USDA calf nursery. Total serum protein from each calf was recorded using a handheld refractometer; all calves had total serum protein concentrations $>5.2 \mathrm{~g} /$ $\mathrm{dL}$ and averaged $6.3 \mathrm{~g} / \mathrm{dL}$. At enrollment, each calf was weighed, stratified by BW, and assigned to treatments by randomly placing the 2 calves with the most similar BW to the 2 different planes of nutrition treatments. Calves were housed in elevated individual stainless steel pens $(1.5 \mathrm{~m} \times 0.75 \mathrm{~m})$ with a slotted rubber floor.

Calves were assigned to either a low plane of nutrition $(\mathbf{L P N})$ or a high plane of nutrition $(\mathbf{H P N})$ dietary treatment. All management of calves was identical between treatments. The LPN calves were fed $11.6 \mathrm{~g}$ of $\mathrm{DM} / \mathrm{kg}$ of BW milk replacer powder per day of a $20 \%$ all-milk protein and $20 \%$ fat milk replacer (Table 1; Land O'Lakes Animal Protein Co., Shoreview, MN). The HPN calves were fed $19.2 \mathrm{~g}$ of DM/ $\mathrm{kg}$ of BW milk replacer powder per day of a $28 \%$ all-milk protein and $20 \%$ fat milk replacer (Table 1; Land O'Lakes Animal Protein Co.). The milk replacer for each calf was weighed out individually and reconstituted to $14 \%$ DM and fed at approximately $37^{\circ} \mathrm{C}$. Calves were fed twice daily at 0700 and $1900 \mathrm{~h}$ for the duration of study. No calf starter or water was offered during the study. In addition, no electrolytes were offered to any calf because no calf had a fecal score of 4 . The calves were given approximately $24 \mathrm{~h}$ to adapt to their treatment and new environment before experimental measurements started. Therefore, the calves ranged from 30 to $36 \mathrm{~h}$ at the start of the observation period. The study was divided into two 72-h periods starting at $1200 \mathrm{~h}$, and the entire observation period was $6 \mathrm{~d}$ in length.

\section{Health Observations}

Fecal scores were assigned on a 1 to 4 categorical scale, where 1 = firm, well-formed (not hard); $2=$ soft, pudding-like; 3 = runny, pancake batter; $4=$ liquid, splatters, pulpy orange juice (Larson et al., 1977). Calf disposition was assessed before each feeding as $1=$ alert, strong suckle reflex; $2=$ slightly depressed and response to stimuli slightly decreased, still strong suckle reflex; 3 = lethargic, respond to stimuli more severely depressed, weak suckle reflex; $4=$ lying lateral, response to stimuli greatly decreased, unable to stand or suckle. The hydration score was assessed before each feeding as $1=$ normal, well hydrated; $2=$ mild dehydration, able to stand, slight skin tenting less than $3 \mathrm{~s}$, eyes not sunken; 3 = moderate dehydration, able to stand, slight skin tenting less than $5 \mathrm{~s}$, eyes sunken; $4=$ severely dehydrated, unable to stand, skin tenting greater than 5 s, eyes sunken. 


\section{Sampling and Analysis}

Calves were individually weighed at arrival and immediately before and at the end of each of the 2 experimental periods. Milk replacer refusals were recorded approximately $30 \mathrm{~min}$ after each feeding. Ten milliliters of peripheral blood was collected from a jugular vein into an evacuated tube with $\mathrm{K}_{2}$ EDTA immediately before measuring each calf's BW. Plasma was immediately obtained after centrifugation at $1,200 \times g$ for 15 min and stored at $-40^{\circ} \mathrm{C}$ until subsequently analyzed. Plasma was analyzed for glucose and urea nitrogen using a micro-manual method according to the manufacturer's instructions (Stanbio Laboratory, Boerne, TX). Intra- and interassay coefficients of variation were 3.2 and $4.1 \%$ for plasma glucose concentrations and 3.8 and $4.5 \%$ for plasma urea nitrogen concentrations.

Total fecal collection was performed during each 72 -h experimental period. Fecal material was collected from underneath the slatted floor pen. Any residues of fecal material that remained on the slatted floor were also collected. Within $3 \mathrm{~h}$ of defecation, each fecal sample was weighed and placed in a bag for each calf during each period. The fecal samples were stored at $-40^{\circ} \mathrm{C}$ until subsequently analyzed. To prevent urine from mixing with the fecal samples, 3 diapers (Guards for Men, Depends, Kimberly-Clark Inc., Neenah, WI) were attached to each calf using an extra-large washable male canine wrap. When the diapers were wet, they were replaced with new diapers. Total urine collection was collected for the last $24 \mathrm{~h}$ of each experimental period. The diapers were removed during the total urine collection and calves were continuously monitored over the entire 24-h period and immediately after either defecation or urination the sample was collected, measured, and stored. A frame made from PVC pipe was lined with a plastic liner and placed under each pen. The urine was collected from the plastic liner using a $60-\mathrm{mL}$ syringe. Urine was acidified by adding approximately 1 $\mathrm{mL}$ of $5 \mathrm{~N} \mathrm{HCl}$ for every $30 \mathrm{~mL}$ of urine collected. Urine samples were stored at $-40^{\circ} \mathrm{C}$ until analyzed.

Fecal samples were analyzed for DM percentage using a 2-stage drying process. First, the samples were dried at $55^{\circ} \mathrm{C}$ in a forced-air oven until the weight no longer changed, which was approximately $4 \mathrm{~d}$ for this study. Samples were ground using a coffee grinder and subsequently used for subsequent analytical measurements of nitrogen, OM, ash, and energy. Additional 5-g samples were further dried at $100^{\circ} \mathrm{C}$ for $24 \mathrm{~h}$ in a forced-air oven to adjust to a $100 \%$ DM basis. Milk replacer samples, $5 \mathrm{~g}$, were dried at $100^{\circ} \mathrm{C}$ for $24 \mathrm{~h}$ to determine DM percentage. Fecal and milk replacer samples were analyzed for energy in duplicate using a 6100 compensated jacket bomb calorimeter (Parr Instrument Company, Moline,
IL). Intra- and interassay coefficients of variation were 2.1 and $2.4 \%$, respectively. Organic matter and ash contents of fecal and milk replacer samples were determined after the dry oxidation of samples at $550^{\circ} \mathrm{C}$ in a furnace for $5 \mathrm{~h}$ (Cole Parmer, Vernon Hills, IL). Fecal and milk samples were analyzed for total nitrogen on a TruMac carbon, nitrogen, and sulfur autoanalyzer (Leco Corporation, St. Joseph, MI). Intra- and interassay coefficients of variation were 2.3 and $2.5 \%$, respectively. Urine was also analyzed for the concentrations of energy and nitrogen. Urine energy were determined by adding $3 \mathrm{~mL}$ of urine to $0.5 \mathrm{~g}$ of dried cellulose and then dried for another $48 \mathrm{~h}$ at $50^{\circ} \mathrm{C}$ before analysis in the bomb calorimeter. The concentration of energy in urine was determined from the difference of analyzing $0.5 \mathrm{~g}$ of dried cellulose alone. Intra- and interassay coefficients

Table 1. The formulated and analyzed nutrient content of the milk replacer fed to Jersey calves

\begin{tabular}{lcc}
\hline & \multicolumn{2}{c}{ Milk replacer $^{1}$} \\
\cline { 2 - 3 } Nutrient & LPN & HPN \\
\hline Formulated & & \\
CP, \% & 20 & 28 \\
Ether extract, \% & 20 & 20 \\
Acid detergent fiber (max), $\%$ & 0.15 & 0.15 \\
ME, ${ }^{2}$ Mcal/kg & 4.65 & 4.75 \\
Calcium, \% & 0.75 & 0.75 \\
Phosphorus, \% & 0.7 & 0.7 \\
Vitamin A (min), IU/kg & 44,000 & 44,000 \\
Vitamin D ${ }_{3}$ (min), IU/kg & 11,000 & 11,000 \\
Vitamin E (min), IU/kg & 220 & 330 \\
Analyzed & & \\
DM, \% & & 90.7 \\
OM, \% & 88.4 & 80.8 \\
CP, \% & 21.8 & 30.7 \\
Gross energy, Mcal/kg & 5.50 & 5.68 \\
ME, Mcal/kg & 4.55 & 4.64 \\
Ash, \% & 11.6 & 10.3 \\
\hline
\end{tabular}

${ }^{1}$ Two commercial milk replacers were fed (Land O'Lakes Animal Milk Products Co., Shoreview, MN); LPN = low plane of nutrition and $\mathrm{HPN}=$ high plane of nutrition. Both milk replacers were formulated with similar macro- and micro-ingredients and included: dried whey, dried whey protein concentrate, dried whey product, dried skim milk, dried milk protein, animal fat, lecithin, polysorbate 80 , dicalcium phosphate, calcium carbonate, brewers dried yeast, vitamin A acetate, $\mathrm{D}-\alpha$ tocopherol acetate, vitamin $\mathrm{D}_{3}$, thiamine monohydrate, riboflavin, niacin supplement, folic acid, vitamin $\mathrm{B}_{12}$ supplement, choline chloride, zinc methionine complex, manganese methionine complex, copper lysine complex, iron AA complex, ethylenediamine dihydroiodide, selenium yeast, and natural and artificial flavor.

${ }^{2}$ Calculated based on NRC (2001).

${ }^{3}$ Dry matter was determined after drying in a forced-air oven at $100^{\circ} \mathrm{C}$ for $24 \mathrm{~h}$. Crude protein was estimated by determining the concentration of nitrogen on a TruMac nitrogen autoanalyzer (Leco Corporation, St. Joseph, MI), and gross energy was determined by combusting $1 \mathrm{~g}$ of oven-dried milk replacer in a 6100 water jacket bomb calorimeter (Parr Instrument Company, Moline, IL). Organic matter and ash were determined after dry oxidation at $550^{\circ} \mathrm{C}$ for $5 \mathrm{~h}$ in a furnace (Cole Parmer, Vernon Hills, IL).

${ }^{4}$ Calculated from data collected in this study. Reported in Table 3. 
of variation were 2.4 and $2.4 \%$, respectively. Lastly, the nitrogen concentrations of urine were also analyzed on a TruMac carbon, nitrogen, and sulfur autoanalyzer (Leco Corporation). Intra- and interassay coefficients of variation were 2.6 and $2.8 \%$, respectively.

\section{Energy Partitions and Nitrogen Calculations}

Apparent digestible energy and ME were calculated as gross energy intake - fecal energy and gross energy intake - (fecal energy + urinary energy), respectively. The apparent digestible energy and ME efficiencies were calculated by dividing each respective partition of energy by the gross energy intake $\times 100$. Further, the apparent digestible energy and ME contents of each milk replacer was calculated as apparent digestible energy and ME intake per kilogram of DMI of each milk replacer, respectively. Apparent digestibilities of $\mathrm{OM}$ and ash were calculated as the intake of each - the fecal excretion of each $\times 100$.

The apparent digestible nitrogen was calculated as nitrogen intake - fecal nitrogen. Further, the apparent efficiency of digestible nitrogen was estimated by dividing the apparent digestible nitrogen by total nitrogen intake $\times 100$. Nitrogen retention was calculated as nitrogen intake - (fecal nitrogen + urinary nitrogen), and the efficiency of nitrogen retention was estimated by dividing the nitrogen retained by the nitrogen intake $\times 100$.

\section{Statistical Analyses}

All continuous, repeated data were analyzed by restricted maximum-likelihood ANOVA using the MIXED procedure of SAS (v.9.3, SAS Institute Inc., Cary, NC). A compound symmetry covariance structure for the within-calf measurements was fit because only 2 observations were available per calf. Additionally, fecal score data were analyzed both using the mean fecal score of all defecations per period and analyzed by ANOVA as well as the pooled fecal sample per period was given a fecal score, and these data were analyzed using a chisquared goodness of fit test using the FREQ procedure of SAS (v.9.3). Normality of the residuals was evaluated using the Shapiro-Wilk statistic and normal probability plots using the UNIVARIATE procedure of SAS (v.9.3). The final model included the fixed effects of treatment, period, and treatment $\times$ period and block as a random effect. Pairwise differences were performed at each time interval using a sliced effect multiple comparison approach with a Tukey-Kramer adjustment. Differences of $P \leq 0.05$ were considered significant, and $0.10 \geq P$ $>0.05$ was considered a tendency.

\section{RESULTS}

\section{Intakes, Performance, and Fecal Characteristics}

Body weights, ADG, and intakes of milk replacer are reported in Table 2. No difference $(P=0.895)$ was

Table 2. Influence of plane of nutrition on milk replacer intake, growth performance, and fecal and urine excretion of Jersey calves during the first week of life ${ }^{1}$

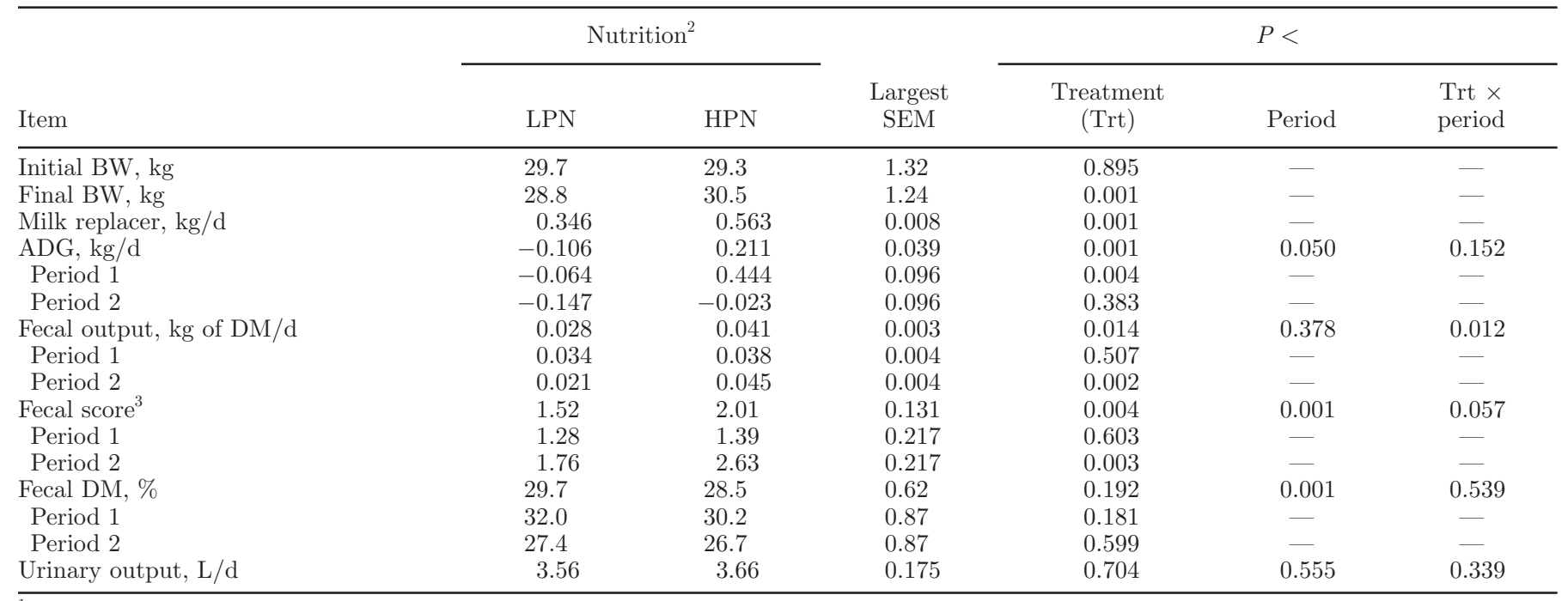

${ }^{1}$ The experiment was divided into 2 periods, period $1=1$ to $3 \mathrm{~d}$ and period $2=4$ to $7 \mathrm{~d}$.

${ }^{2} \mathrm{LPN}=$ low plane of nutrition were fed $13.0 \mathrm{~g}$ of a $20 \% \mathrm{CP}$ and $20 \%$ fat milk replacer per kilogram of BW at the start of the first period $(\mathrm{n}=$ 6 ); HPN = high plane of nutrition were fed $21.0 \mathrm{~g}$ of a $28 \% \mathrm{CP}$ and $20 \%$ fat per kilogram of BW at the start of the first period $(\mathrm{n}=6)$.

${ }^{3}$ Fecal score is assessed as $1=$ firm, well-formed (not hard); $2=$ soft, pudding-like; $3=$ runny, pancake batter; $4=$ liquid, splatters, pulpy orange juice. 
found in initial BW of the calves at enrollment. Calves fed the HPN consumed more milk replacer by design of the experiment than the LPN calves. The increased consumption of milk replacer resulted in an increased $(P=0.001)$ ADG of the HPN calves during the first period; however, during the second period, although numerically greater, ADG was not different $(P=0.383)$ from the LPN calves. Calves fed the HPN had a greater $(P=0.001)$ final BW.

The fecal characteristics of calves fed either the LPN or HPN are reported in Table 2. A treatment $\times$ period interaction $(P=0.012)$ was found of fecal output per day, whereas no treatment difference was found during period $1(P=0.507)$, but the HPN calves excreted more fecal DM during period $2(P=0.002)$. Similarly, a tendency was found for a treatment $\times$ period interaction $(P=0.057)$ on fecal score. The HPN calves had greater mean fecal scores during period $2(P=0.003)$, but were not different during period $1(P=0.603)$. In agreement, no difference was found in the distribution of calves with various fecal scores for the fecal composite during period $1(P=0.505)$, but a tendency $(P=$ 0.059 ) was observed for LPN to have fewer calves with a fecal score 3 during period 2. Despite differences in fecal scores, no difference was found in the DM percentage of feces $(P=0.192)$. Additionally, no difference was observed in the volume of urine excreted between treatments $(P=0.704)$.

\section{Partitions of Energy, Digestibilities of OM and Ash, and Plasma Glucose}

Gross energy intake, fecal energy, urinary energy, as well as digestible energy and ME are reported in Table 3. During the first period, no treatment differences $(P$ $>0.229$ ) were found in either the total fecal or urinary energy excreted; however, during the second period, the HPN calves excreted more fecal $(P=0.011)$ and urinary energy $(P=0.064)$. The increased gross energy intake of the HPN calves resulted in greater $(P=0.001)$ digestible energy and ME intakes during both periods; however, no differences $(P>0.355)$ were found between planes of nutrition when both digestible energy and ME were expressed as a percentage of gross energy intake.

Treatment $\times$ period interactions were observed for OM $(P=0.017)$ and ash $(P=0.001)$ digestibilities (Table 3). A tendency $(P=0.054)$ was observed for HPN calves to have a greater OM digestibility during period 1 , but not during period $2(P=0.162)$. Similarly, the HPN calves had a greater digestibility $(P=$ 0.001 ) of ash during period 1 , but not during period 2 $(P=0.426)$. Plasma glucose was numerically greater $(P=0.185)$ among the HPN calves throughout the experiment.

\section{Digestibility of Nitrogen, Plasma Urea Nitrogen, and Nitrogen Retention}

The partitions of dietary nitrogen and plasma urea nitrogen are reported in Table 4 . A treatment $\times$ period $(P=0.014)$ interaction was observed for fecal nitrogen, whereas during period 1 no difference $(P=0.319)$ was found between planes of nutrition, but during period 2 the HPN calves excreted more fecal nitrogen $(P=$ 0.001). Calves fed the HPN excreted more urinary nitrogen during both periods $(P=0.001)$. During the first period, the HPN calves had a greater percentage $(P=0.004)$ of digestible nitrogen. Further, when nitrogen retention was expressed relative to nitrogen intake, the HPN during the first period retained a greater percentage $(P=0.004)$. In contrast, no differences $(P>$ 0.798 ) were found in the percentages of intake nitrogen captured as digestible or retained between planes of nutrition during the second period. No treatment or treatment $\times$ period interaction $(P>0.130)$ was found for plasma urea nitrogen concentrations; however, when sliced by day the HPN calves had greater $(P=0.039)$ plasma urea nitrogen concentrations immediately before initiating the first period (Figure 1).

\section{DISCUSSION}

This study investigated the apparent digestibilities of energy, OM, ash, and nitrogen as well as determined nitrogen retention of Jersey calves fed different planes of milk replacer during the first week of life. Apparent digestibilities were likely slightly overestimated because of the total fecal collection methods used in the current study. Additionally, the assumption that these calves were in a pseudo steady state is likely also not completely valid. The calves were given a short adaptation period, approximately $1 \mathrm{~d}$ or 2 milk replacer feedings, to adapt to their environment and treatment, and pass meconium feces. Although this adaptation period was short, the objectives of this study were to evaluate apparent digestibility of energy, OM, ash, and nitrogen fed different planes of milk replacer as soon after birth as conceivably possible. Cannon et al. (2010) reported a short mean retention time of Holstein calves fed milk replacer, only $8.4 \mathrm{~h}$, which helps support the short adaptation period. Further, it was decided to break the entire observation period into two 72 -h periods because it is known that rapid changes occur in both the physiology and metabolism of calves during the first week of life (Guilloteau et al., 2009), but some of the period differences observed could be due to contamination of meconium feces, nutrients from colostrum, or both, in period 1 collections. 
The calves fed the HPN tolerated the additional nutrients well during the first week of life. The HPN calves had increased ADG, ME, and nitrogen retention compared with calves fed the LPN. The percentage of intake energy that was either digested or available for metabolism was not different between treatments. Organic matter and ash digestibilities were greater during the first period among calves fed the HPN, but were not different from calves fed the LPN during the second period. Similarly, digestible nitrogen when expressed as a percentage of intake nitrogen were greater for calves fed the HPN during the first period and not different during the second period when compared with calves fed the LPN.
In agreement with others, feeding a HPN during the first week of life increased ADG of calves (Bartlett et al., 2006; Ballou et al., 2013). Fecal scores of calves fed a HPN were greater; however, no scours (i.e., fecal score of 4) were observed among any calf during the study. Furthermore, the DM percentages of feces were not different between calves fed a HPN or LPN. Bascom et al. (2007) also reported that calves fed a HPN had greater fecal scores, but others reported no differences in fecal scores between calves fed a HPN and LPN (Ballou et al., 2013; Obeidat et al., 2013). No study has observed a greater fecal score among LPN calves when compared with HPN. These data indicate that under certain circumstances calves fed a HPN will have greater fecal

Table 3. Influence of plane of nutrition on partitions of gross energy intake, energy content of milk replacers fed to Jersey calves, and digestibility of $\mathrm{OM}$ and ash during the first week of life ${ }^{1}$

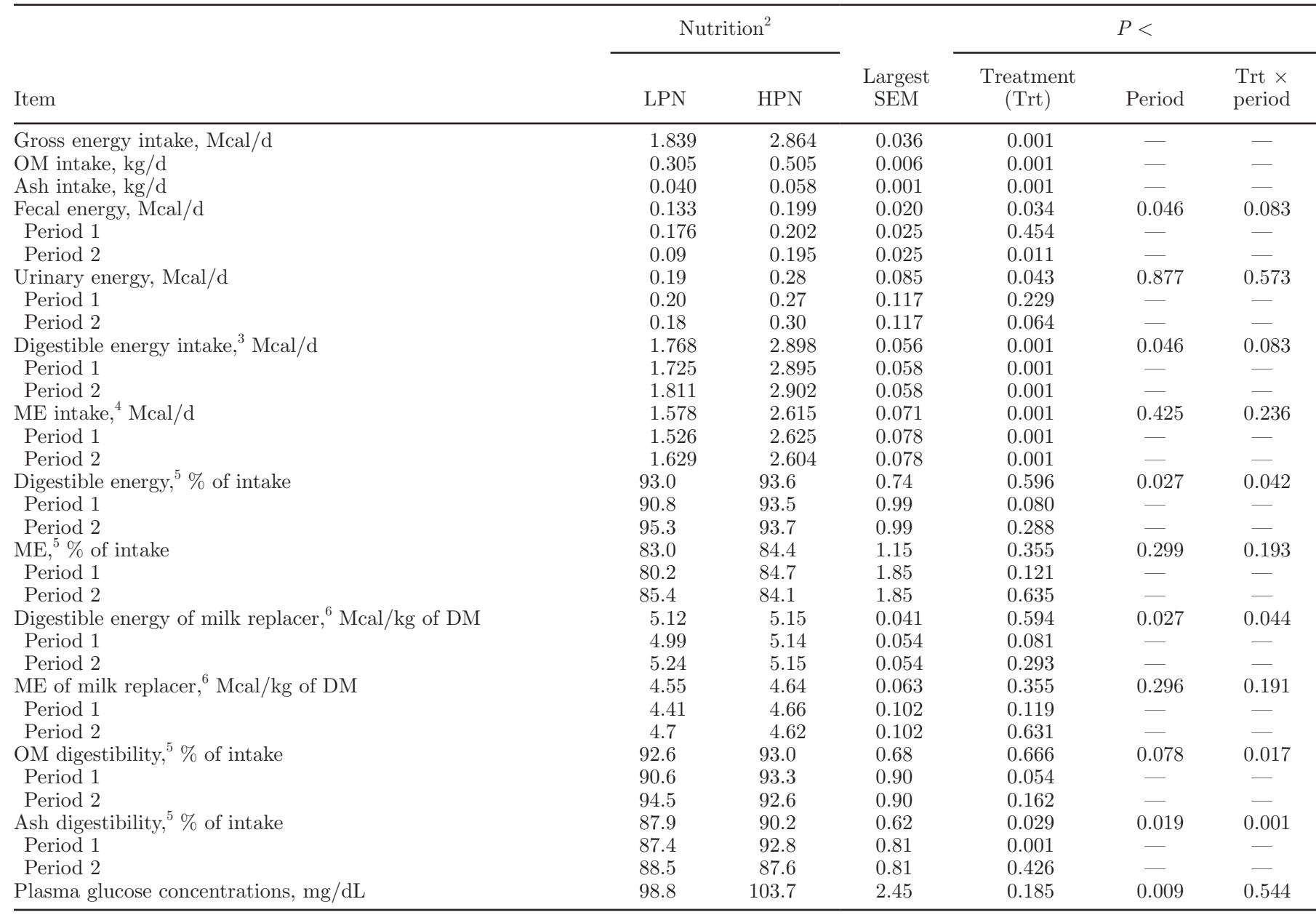

${ }^{1}$ The experiment was divided into 2 periods, period $1=1$ to $3 \mathrm{~d}$ and period $2=4$ to $7 \mathrm{~d}$.

${ }^{2} \mathrm{LPN}=$ low plane of nutrition were fed $13.0 \mathrm{~g}$ of a $20 \% \mathrm{CP}$ and $20 \%$ fat milk replacer per kilogram of BW at the start of the first period $(\mathrm{n}=$ $6) ; \mathrm{HPN}=$ high plane of nutrition were fed $21.0 \mathrm{~g}$ of a $28 \% \mathrm{CP}$ and $20 \%$ fat per kilogram of BW at the start of the first period $(\mathrm{n}=6)$.

${ }^{3}$ Digestible energy intake $=$ (gross energy intake - fecal energy $)$.

${ }^{4}$ Metabolizable energy intake $=[$ gross energy intake $-($ fecal energy + urinary energy + gas energy $)]$. Gas energy was estimated as $1 \%$ of the gross energy intake.

${ }^{5}$ Digestibilities calculated as (intake - fecal excretion)/intake $\times 100$.

${ }^{6}$ Digestible and ME contents of milk replacers were calculated as (intake of each energy, Mcal/intake of milk replacer, kg of DM). 


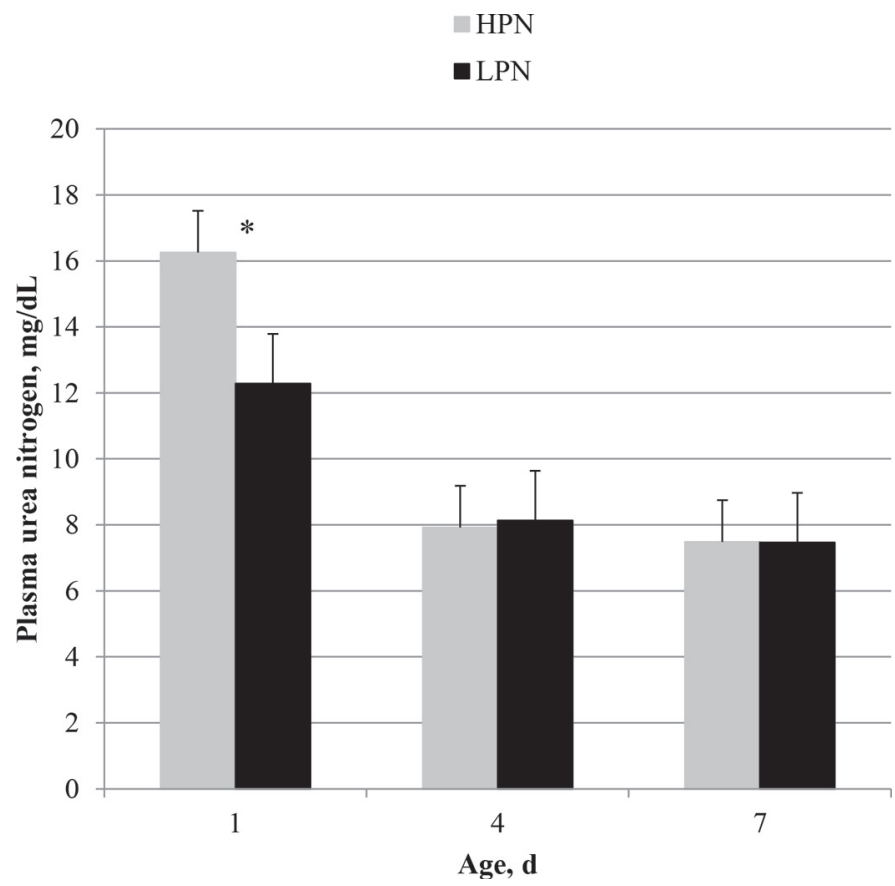

Figure 1. Plasma urea nitrogen concentrations (LSM \pm SEM) during the first week of life when calves were fed different planes of milk replacer nutrition. Calves were either fed a high plane of nutrition (HPN; $20 \mathrm{~g} / \mathrm{kg}$ of BW of a $28 \% \mathrm{CP}$ and $20 \%$ fat milk replacer) or a low plane of nutrition (LPN; $14.5 \mathrm{~g} / \mathrm{kg}$ of BW of a $20 \% \mathrm{CP}$ and $20 \%$ fat milk replacer). Calves were fed their respective treatments for 24 $\mathrm{h}$ before the first blood collection taken at $1 \mathrm{~d}$ of age. Calves fed the HPN had greater plasma urea nitrogen concentrations on $d 1$ of the study $(P=0.001)$. No differences were observed between treatments of plasma urea concentrations on either d $4(P=0.905)$ or $7(P=0.993)$. scores than calves fed a LPN. The greater fecal scores in some studies resulted from increased scours among calves fed a HPN (Grieve et al., 1973; Huber et al., 1984). Additionally, Jenny et al. (1981) reported that both fluid intake and milk replacer DM concentration had positive linear effects on fecal scores and duration of scours for Holstein calves during the first $6 \mathrm{wk}$ of life. In contrast, Nonnecke et al. (2003) suggested that the greater volume of fluid fed to HPN calves caused the greater fecal scores without an increased incidence of scouring. The current data further indicate that fecal scores alone are not the best indicator of gastrointestinal health when comparing calves fed different planes of nutrition because the HPN had greater fecal scores, but the DM percentage of feces was not different from calves fed a LPN. The greater mass of feces among calves fed a HPN may make the feces appear looser than feces with a similar DM percentage from calves fed a LPN. Future studies comparing planes of milk or milk replacer nutrition should measure fecal DM percentage in addition to incidences of scouring (i.e., a fecal score 4). Additionally, these data also indicate that the fecal DM percentages of these healthy Jersey calves, irrespective of plane of milk replacer nutrition, were relatively high during the first week of life when compared with Holstein calves challenged with Cryptosporidium parvum $24 \mathrm{~h}$ after birth (Bellosa et al., 2011). Bellosa et al. (2011) reported mean fecal DM percentages of $20.9,16.3,9.6$, and $5.8 \%$ for calves with fecal scores of 1, 2, 3, and 4, respectively; however, the ranges in fecal DM percentage were large for all fecal scores. Liang (2015) reported fecal DM percentages of

Table 4. Influence of plane of nutrition on nitrogen retention in Jersey calves during the first week of life

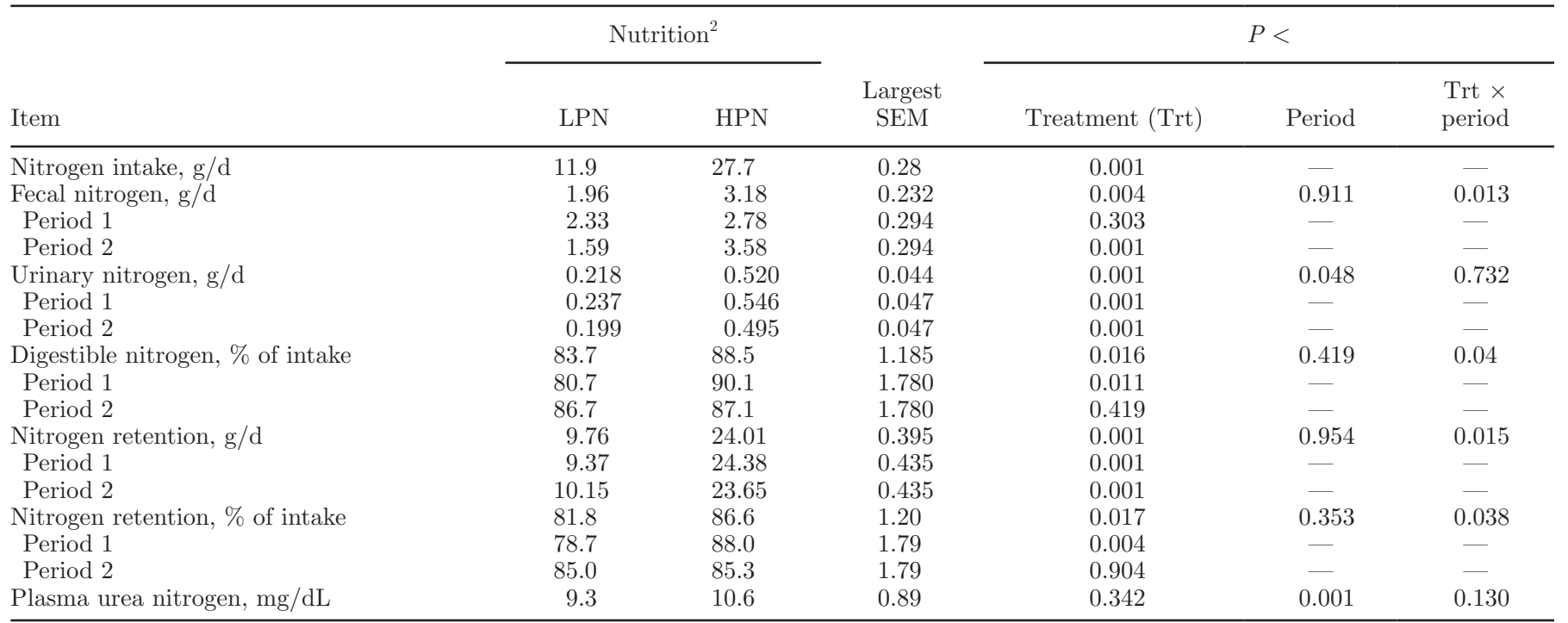

${ }^{1}$ The experiment was divided into 2 periods, period $1=1$ to $3 \mathrm{~d}$ and period $2=4$ to $7 \mathrm{~d}$.

${ }^{2} \mathrm{LPN}=$ low plane of nutrition were fed $14.5 \mathrm{~g}$ of a $20 \% \mathrm{CP}$ and $20 \%$ fat milk replacer per kilogram of BW at the start of the first period (n = $6)$; HPN $=$ high plane of nutrition were fed $20.0 \mathrm{~g}$ of a $28 \% \mathrm{CP}$ and $20 \%$ fat per kilogram of BW at the start of the first period $(\mathrm{n}=6)$. 
Jersey calves every other day from 10 to $24 \mathrm{~d}$ of age, and noticed as fecal score increased the fecal DM percentage decreased. He reported fecal DM percentages of $28.9,23.6,20.2$, and $13.8 \%$ for fecal scores of $1,2,3$, and 4 , respectively, when calves were fed a high plane of milk replacer and challenged orally with Citrobacter rodentium. The exact reason for the greater fecal DM percentages of calves in the current study is unknown, but could it could be related to the fact these calves did not have access to water and were not fed a calf starter, as well as age and infection/disease status.

No differences were observed in the partitions of energy as a percentage of intake between treatments in current study. The HPN calves had greater gross energy intake, but also excreted more energy as fecal and urinary energy. The apparent digestible energy and ME intakes, in megacalories per day, were greater for HPN calves; however, the digestible energy and ME, expressed relative to gross energy intake, were not different between treatments. In agreement, Diaz et al. (2001) reported no difference in the apparent digestible energy, expressed relative to intake, among Holstein calves fed 1,3 , or $4 \%$ of $\mathrm{BW}$ as DM from milk replacer from wk 2 to 7 of life. In the current study, the digestibility of energy was high, greater than $92.7 \%$. These data are consistent with Gerrits et al. (1996), which reported the digestibility of energy from milk replacer for older Holstein calves, with BW ranging from 80 to $160 \mathrm{~kg}$, was greater than 94\%. The apparent digestible energy increased slightly during the second period, but it is likely that the apparent digestibility of the first period was slightly underestimated because of residual meconium feces and undigested nutrients from colostrum. Similar to the apparent digestible energy, no treatment difference was found in apparent ME, when expressed to gross energy intake. We assumed that a constant $1 \%$ of gross energy was lost as gas energy, and in the current study 9.6 and $9.4 \%$ of gross energy was lost as urinary energy among LPN and HPN calves, respectively. Therefore, the additional gross energy consumed by calves fed the HPN during the first week of life was digested, absorbed, and available for metabolism. The additional intake of ME among the HPN calves increases the efficiency of retained energy relative to the gross energy intake (Bartlett et al., 2006). This is because the maintenance energy requirements are further diluted at greater ME intakes. Plasma glucose concentrations were not different between treatments, but the HPN had numerically greater concentrations. The lack of statistical difference is likely due to the sample size of 6 , but these data are at least consistent with others that have reported that HPN often have greater plasma glucose concentrations (Obeidat et al., 2013; Ballou et al., 2015).
By design of this study, the HPN calves had greater nitrogen intakes than the LPN calves. Fecal nitrogen output was not different between treatments during period 1, but was greater among the HPN calves during the second period. This resulted in a greater percentage of nitrogen digested when expressed relative to intake among the HPN calves during the first period. The lack of a difference in fecal nitrogen during period 1, as noted before, may be partially due to residual meconium feces or undigested nitrogen from colostrum. Assuming a constant amount of meconium feces and undigested nitrogen in the total fecal collection during period 1 for both LPN and HPN treatments, the apparent digestibility would be underestimated to a greater degree among the LPN calves. This could partially explain the reduced apparent digestible nitrogen as a percentage of intake among the LPN calves during the first period. A similar explanation could explain the greater digestibility of ash during the first period. However, similar to the second period in the current study, Diaz et al. (2001) reported no difference in the apparent digestibility of nitrogen between the Holstein calves, ranging in BW from 80 to $160 \mathrm{~kg}$, fed 1, 3, or $4 \%$ of their BW as milk replacer DM. Apparent digestibility of nitrogen in that study ranged from 92.5 to $94.2 \%$, which is slightly greater than was observed in the current study. This difference could be attributed to either the age or breed of the calves that were studied.

Some of the additional nitrogen that was digested among the HPN calves was lost as urinary nitrogen. Plasma urea nitrogen concentrations were greater among HPN calves at the start of period 1, but no treatment differences were found at the end of periods 1 and 2. These data are consistent with reports that plasma urea nitrogen concentrations are greater among calves fed a HPN for the first few days to week of life and then are not different from calves fed a LPN for the remainder of the preweaned period (Obeidat et al., 2013; Ballou et al., 2015). Urinary excretion of nitrogen, when expressed relative to nitrogen intake, was only 1.96 and $2.01 \%$ for the LPN and HPN calves, respectively. Therefore, most of the digestible nitrogen was retained irrespective of plane of milk replacer nutrition. This indicates that calves as early as the first week of life can digest, absorb, and incorporate AA into tissue growth from a high-quality all-milk protein milk replacer with a high efficiency. In order for the calf to survive ex utero, the gastrointestinal tract must adapt quickly to enteric stimulation.

Guilloteau et al. (2009) reviewed the ontogenesis of the gastrointestinal tract that occurs in neonatal calves. During the first week of life fetal-type enterocytes, which are highly vacuolated, are replaced with more adult-like enterocytes. This process occurs in a 
proximal-distal pattern and is influenced by local bioactive compounds, and likely contributes to closure of the intestines. Pancreatic secretions respond to feeding within the first day after birth, but increase further during the first week of life. Intestinal activities of lactase and aminopeptidase are high at birth and actually decrease thereafter. Guilloteau et al. (2009) also reported that the activity of intestinal enzymes was dependent on the quantity and quality of feed ingested during the first week of life. Taken together, with the current data, the gastrointestinal tract of healthy neonatal calves is well suited to digest and absorb nutrients, even when fed at a HPN. Further, incorporation of amino nitrogen into tissue growth is great during the first week of life. In addition to lean tissue growth, Schaart et al. (2005) reported a high proportion of dietary threonine was incorporated into intestinal tissues in young piglets. These data reiterate the dynamic state of the gastrointestinal tract, especially during early life.

\section{CONCLUSIONS}

Although the gastrointestinal tract of neonatal calves are adapting to the ex utero environment during the first week of life, it is capable of digesting and absorbing the additional nutrients when healthy calves are fed a higher plane of milk replacer nutrition. The additional energy and amino nitrogen absorbed by calves fed the higher plane of nutrition were available for tissue growth. Future research should determine how those additional nutrients influence the integrity of the gastrointestinal tract of neonates, as they are highly susceptible to enteric disease at this stage of life.

\section{ACKNOWLEDGMENTS}

This research was funded by a grant from the Texas Animal Nutrition Council (txanc.org). The milk replacer for the study was donated by Land O'Lakes Animal Protein Co. of Shoreview, MN. The authors thank Tyler Harris with Texas Tech University and Jeff Dailey with USDA-ARS Livestock Issues Research Unit for their help collecting the data.

\section{REFERENCES}

Ballou, M. A. 2012. Immune responses of Holstein and Jersey calves during the preweaning and immediate postweaned periods when fed varying planes of milk replacer. J. Dairy Sci. 95:7319-7330

Ballou, M. A., C. J. Cobb, T. J. Earleywine, and B. S. Obeidat. 2013. Breed and plane of milk replacer nutrition influence the performance of pre and postweaned dairy calves. Prof. Anim. Sci. 29:116-123.

Ballou, M. A., D. L. Hanson, C. J. Cobb, B. S. Obeidat, M. D. Sellers, A. R. Pepper-Yowell, J. A. Carroll, T. J. Earleywine, and S.
D. Lawhon. 2015. Plane of nutrition influences the performance, innate leukocyte responses, and resistance to an oral Salmonella enterica serotype Typhimurium challenge in Jersey calves. J. Dairy Sci. 98:1972-1982.

Bartlett, K. S., F. K. McKeith, M. J. VandeHaar, G. E. Dahl, and J. K. Drackley. 2006. Growth and body composition of dairy calves fed milk replacers containing different amounts of protein at two feeding rates. J. Anim. Sci. 84:1454-1467.

Bascom, S. A., R. E. James, M. L. McGilliard, and M. Van Amburgh. 2007. Influence of dietary fat and protein on body composition of Jersey bull calves. J. Dairy Sci. 90:5600-5609.

Bellosa, M. L., D. V. Nydam, J. L. Liotta, J. A. Zambriski, T. C. Linden, and D. D. Bowman. 2011. A comparison of fecal percent dry matter and number of Cryptosporidium parvum oocysts shed to observational fecal consistency scoring in dairy calves. J. Parasitol. 97:349-351.

Cannon, S. J., G. C. Fahey Jr., M. R. Murphy, C. L. Dikeman, B. L. Miller, and J. K. Drackley. 2010. Inclusion of psyllium in milk replacer for neonatal calves. 1. Effects on growth, digesta viscosity, rate of passage, nutrient digestibilities, and metabolites in blood. J. Dairy Sci. 93:3652-3660.

Diaz, M. C., M. E. Van Amburgh, J. M. Smith, J. M. Kelsey, and E. L. Hutten. 2001. Composition of growth of Holstein calves fed milk replacer from birth to 105-kilogram body weight. J. Dairy Sci. 84:830-842.

Gerrits, W. J., G. H. Tolman, J. W. Schrama, S. Tamminga, M. W. Bosch, and M. W. Verstegen. 1996. Effect of protein and proteinfree energy intake on protein and fat deposition rates in preruminant calves of 80 to $240 \mathrm{~kg}$ live weight. J. Anim. Sci. 74:2129-2139.

Grieve, D. G., W. G. Merrill, and C. E. Coppock. 1973. Sulfur supplementation of urea-containing silages and concentrates. II. ration digestibility, nitrogen, and sulfur balances. J. Dairy Sci. 56:224228.

Guilloteau, P., R. Zabielski, and J. W. Blum. 2009. Gastrointestinal tract and digestion in the young ruminant: Ontogenesis, adaptations, consequences and manipulations. J. Physiol. Pharmacol. Off. J. Polish Physiol. Soc. 60 Suppl. 3:37-46.

Huber, J. T., A. G. Silva, O. F. Campos, and C. M. Mathieu. 1984. Influence of feeding different amounts of milk on performance, health, and absorption capability of baby calves. J. Dairy Sci. 67:2957-2963.

Jenny, B. F., G. E. Gramling, and T. M. Glaze. 1981. Management factors associated with calf mortality in South Carolina dairy herds. J. Dairy Sci. 64:2284-2289.

Larson, L. L., F. G. Owen, J. L. Albright, R. D. Appleman, R. C. Lamb, and L. D. Muller. 1977. Guidelines toward more uniformity in measuring and reporting calf experimental data. J. Dairy Sci. 60:989-991.

Liang, Y. 2015. The influences of planes of nutrition on development and health of the gastrointestinal tract of calves. MS Thesis. Texas Tech Univ., Lubbock, TX.

NAHMS. 2007. Heifer calf health and management practices in the United States. USDA, ed. USDA:APHIS:VS:CDAH, Fort Collins, $\mathrm{CO}$

Nonnecke, B. J., M. R. Foote, J. M. Smith, B. A. Pesch, and M. E. Van Amburgh. 2003. Composition and functional capacity of blood mononuclear leukocyte populations from neonatal calves on standard and intensified milk replacer diets. J. Dairy Sci. 86:35923604 .

NRC. 2001. Nutrient Requirements of Dairy Cattle. 7th rev. ed. National Academies Press, Washington, DC.

Obeidat, B. S., C. J. Cobb, M. D. Sellers, A. R. Pepper-Yowell, T. J. Earleywine, and M. A. Ballou. 2013. Plane of nutrition during the preweaning period but not the grower phase influences the neutrophil activity of Holstein calves. J. Dairy Sci. 96:7155-7166.

Schaart, M. W., H. Schierbeek, S. R. D. van der Schoor, B. Stoll, D. G. Burrin, P. J. Reeds, and J. B. van Goudoever. 2005. Threonine utilization is high in the intestine of piglets. J. Nutr. 135:765-770.

Soberon, F., E. Raffrenato, R. W. Everett, and M. E. Van Amburgh. 2012. Preweaning milk replacer intake and effects on long-term productivity of dairy calves. J. Dairy Sci. 95:783-793. 